Agro-Science Journal of Tropical Agriculture, Food, Environment and Extension Volume 14 Number 1 January 2015 pp. 24 - 30 ISSN III9-7455

\title{
EVALUATION OF DIFFERENT ACCESSIONS / VARIETIES OF MAIZE IN RELATION TO THEIR ANTI-NUTRITIONAL COMPOSITIONS
}

\author{
Abba, N.Y ${ }^{1}$ and Echezona, B.C ${ }^{2}$ \\ Department of Agricultural Science Education \\ Kaduna State College of Education, Gidan-Waya. \\ ${ }^{2}$ Department of Crop Science, University of Nigeria, Nsukka \\ Corresponding Author: banaventure.echezona@unn.edu.ng
}

\begin{abstract}
Maize weevils are known to be among the economically important insect pests of maize in Nigeria. They cause significant damage to maize grains in store. The objective of the study was to assessed the susceptibility of different maize accessions / varieties in relation to their anti-nutritional factors. The experiment was done in Department of Crop Science Laboratory, University of Nigeria, Nsukka using a Complete Randomised Design (CRD) and F-LSD to separate the means. Twenty maize accessions / varieties comprising two hybrids (Sammaz - 15 and 16), fifteen open pollinated varieties (Sammaz$11,14,17,18,20,26,27,28,29,31,32,33,34,35$ and 37) and three local accessions (NSU-P, ENU-E and KAG-W)were used. Sammaz-32 varieties had the least susceptibility index (SI) of 1.79 and was considered as resistant. ENU-E, NSU-P, KAG-W, Sammaz - 11, 14, 15, 16, 17, 20, 26, 27, 28, 29, 31, 33, 34 and 37 were grouped as moderately resistant because their SI ranged between 2.6 and 5.0 while Sammaz - 17, 33 and 35 were grouped as moderately susceptible with an SI range between 5.6 and 7.5. The correlation studies indicated that phytate (0.190), oxalates (0.177), Tannins (0.102), Lectins $(0.160)$ and Trypsin inhibitor $(0.106)$ had very low and positive insignificant $(p<0.05)$ correlations with susceptibility index. However, very low heritability estimated of these qualities suggests that selection of maize accessions / varieties through them will be unreliable. Path coefficient analysis revealed that percentage Tannins (-0.4127) had the highest direct negative on susceptibility index (SI) with a total correlation of (0.102) that was very low and negligibly positive with three opposing positive indirect effects from \% phytates (0.3092), \%oxalates (0.0235),\% lectins (0.2744) and supportive indirect effect from \% Try (-0.0899) The heritability estimate of percentage tannins could be considered to make it the most reliable anti-nutritional factor for use in the selection of the maize accessions / varieties in the study for improvement against maize weevil attack.
\end{abstract}

Keywords: Anti-nutrients, Sitophilus zeamais, accessions / varieties, susceptibility index, resistant, correlation studies, path coefficients selection.

\section{INTRODUCTION}

Maize, Zea mays $L$. belongs to the family poaceae or gramineae. Maize is an important food and feed in the world, serving as a source of carbohydrates, proteins and minerals (Ogunniyi, 2011). Post harvest storage insect pests cause serious losses to cereals in both quality and quantity and most cases predispose the stored grains to secondary attack by disease causing pathogens (Mwololo, 2013). Dasbak, et al., (2009) reported that developing countries are adapting the use of resistant grain varieties to control grain weevils as a popular alternative to the use of chemicals to avoid attendant risk problems of death, environmental pollution and cost associated with pesticide usage.

http://dx.doi.org/10.4314/as.v14i1.3
Plant species encounter a basic dilemma in the amount of adaptation energy they must allocate to growth versus that, which they must allocate to defenses necessary for survival in the presence of pathogens and herbivores (Chukwulobe, 2013). Plants re faced with a struggle, they must grow fast enough to compete, yet they must also divert energy for the synthesis of secondary metabolites to ward off pathogens and herbivores (Cordain, 2006).

Cereal grains which are the seeds of grasses (gramminae) contain a variety of metabolites which can either be toxic, antinutritional, benign or somewhere in-between, depending upon the physiology of the consumer animal (Cordain, 2006). Some secondary 
metabolites and their anti-nutritional effects include: Phenolic acid, alkyresorcinols, alphaamylase inhibitors, lectins, phytates, oxalates, tannins, glycosinolates, cyanogenic glycoside, falvonoidsiso flavones, etc.

\section{MATERIALS AND METHODS}

The study was carried out between April and June 2012, which was the yearly peak period for exponential pest activity of S.zeamais in the store within this ecological zone.

The study was conducted at the department of crop science, University of Nigeria, Nsukka, Nigeria. Nsukka is located at latitude $06^{\circ} 52^{\prime} \mathrm{N}$ and longitude $077^{0} 24^{\prime}$ and at an elevation of $447.26 \mathrm{~m}$ above sea level. The prevailing mean temperature and relative humidity during the experimental period were $29+3^{0} \mathrm{C}$ and $75+5 \%$, respectively. The area is characterized with wet and dry seasons. The wet seasons are bi-modal distributed with peaks in July and September of each year. 15 open pollinated varieties (Sammaz - 11, 14, 17, 18, 20, 26, 27, 28, 29, 31, 32, 33, 3435 and 37), two hybrids (Sammaz - 15 and 16) for the study were gotten from Institute for Agricultural Research (IAR), Ahmadu Bello University, Zaria and three land races (ENU-E, KAG-W and NSU-P). The anti-nutrients (phytates, tannins, lectins, oxalates and chymotrypsin inhibitor in $\mathrm{mg} / 100 \mathrm{~g}$ maize were determined in IAR food technology laboratory in Collaboration with International Institute of Tropical Agriculture (IITA), Ibadan.

\section{a. Culture of $S$. zeamais}

A culture of $S$. zeamais was established to supply similar aged weevils for the experiments. About $10 \mathrm{~kg}$ seeds of a white local variety from Kagoro in Kaduna State were procured and cleaned to remove seeds with visible damaged symptoms. The cleaned seeds were fumigated with half phostoxin tablet for two days and later ventilated for two days to free the seeds from the tablet fumes. The seeds were then a be transferred into four plastic buckets of four litres capacity each and kept in the Crop Science b. Department Laboratory under environmental conditions of $26 \pm 3^{\circ} \mathrm{c}$ and $65-90 \%$ R.H for one c. week. Unsexed adult S.zeamais weevils of between 1 and 15 days were collected from $\mathrm{d}$. infested maize grains in the laboratory and cultured on the cleaned and disinfested maize e. grains (Kagoro white) in the 4 plastic buckets. Each jar containing $3 \mathrm{~kg}$ grains was infested with $\mathbf{c}$ about 150 weevils. The jars were covered with muslin cloth and fixed with a rubber band to allow aeration and to prevent escape of weevils. Seven days after oviposition, all the weevils were removed from each jar by sieving and the emergent adults (at 36-38 days after oviposition) considered to be of fairly the same age were harvested and used to infest the maize varieties in the screening test.

b. Screening the maize varieties for susceptibility/resistance to $S$. zeamais

Maize seeds $(100 \mathrm{~g})$ from each of the maize varieties were placed in $500 \mathrm{ml}$ plastic containers with finely meshed perforations at opposite sides allowing for ventilation and preventing escape of the weevils. The no choice test method, in which the weevils were introduced into each sample of seeds, were as follows. Twenty newly emerged unsexed adult weevils were introduced into the jars to infest the $100 \mathrm{~g}$ seeds of each variety and were kept for seven days for oviposition as reported by Abebe, 2009 and Derera et al. 2001. Seeds of each variety without $S$. zeamais was kept under similar conditions to served as a control. The treatments were arranged in a Complete Randomized Design (CRD) with three replications on the laboratory platforms for observation at $26-29^{\circ} \mathrm{c}, 65-90 \% \mathrm{RH}$ and 14:10 (Light: dark) photoperiod.

\section{Index of Susceptibility (SI)}

The index of susceptibility was calculated using the method of (Howe, 1971; Dobie, 1974; Gharib, 2004; Dasbak et al., 2009; Abebe, 2009).

$\mathrm{S} 1$ was determined by finding the log of the total number of emerged adults divided by the median development time of insect from egg to adult multiplied by 100 as follows:

Susceptibility Index (SI) $=\frac{\text { LogS }}{\mathrm{T}} \mathrm{x} 100$

Where:

$\log \mathrm{S}=$ Logarithm of total number of adult emergents

$\mathrm{T}=$ Median Development Time in days $100=$ percentage $(\%)$

The values of susceptibility indices were categorized into five ranks according to Mensah (1986) as follows:

The values between $0.0-2.5$ were considered resistant variety $(\mathrm{R})$

Those between 2.6-5.0 were considered moderately resistant variety (MR)

The values between, 5.1-7.5 will be considered Moderately susceptible variety (MS)

The values between7.6- 10.0 were considered susceptible variety $(\mathrm{S})$

Those with $\mathrm{S} 1$ values greater than 10.0 were considered highly susceptible variety (HS)

\section{Design and Analysis Employed}

All the experiments were carried out in the laboratory using Complete Randomised Design (CRD). The data collected were subjected to an analysis of variance procedure and mean differences were compared by the use of F-LSD as outlined by Obi (2002). Correlation matrix was 
performed between all the variables assayed. Cause and effect relations of the variables in time and space were determined using path coefficient analysis (Dewey \& Lu, 1959) on phytates, oxalates, tannins, lectins and chymotrypsin inhibitor as some of the major causal anti-nutrient components of maize grain susceptibility to $S$. zeamais.

\section{Anti-nutrients composition (mg/100g) of different maize accessions / varieties}

From table 1, it can be seen that each of the 20 maize accessions / varieties contained more tannins than other anti-nutrients. Sammaz 11 had the highest quantity of $0.072 \mathrm{mg} / 100$ of maize followed by Sammaz 15 with 0.058 $\mathrm{mg} / 100 \mathrm{~g}$ maize both of which remained significantly $(p<0.05)$ higher in phytates than other accessions / varieties. The least quantity of $0.010 \mathrm{mg} / 100 \mathrm{~g}$, maize was recorded in Nsu-p and the general mean for maize accessions / varieties was $0.034 \mathrm{mg}$ phytate per $100 \mathrm{~g}$ maize. Sammaz 37 recorded the highest oxalate content of 0.070 $\mathrm{mg} / 100 \mathrm{~g}$ maize and the least quantity $0.010 \mathrm{mg} / 100 \mathrm{~g}$ maize was recorded in ENU-E. Sammaz 37 differ significantly $(p<0.05)$ with other accessions / varieties in oxalate content compared with other accessions / varieties. The general mean was $0.038 \mathrm{mg}$ oxalate per $100 \mathrm{~g}$ maize for each accession / varieties. With respect to tannin content, Sammaz 15 and 29 recorded the highest quantity of $0.480 \mathrm{mg} / 100 \mathrm{~g}$ each. Both Sammaz 15 and 29 did not differ significantly ( $p>0.05$ ) with Sammaz 16, 11 and 18 but they differ significantly $(\mathrm{p}<0.05)$ and higher than other maize accessions / varieties. Sammaz 35 recorded the least quantity of $0.120 \mathrm{mg}$ tannin per $100 \mathrm{~g}$ maize with a general mean of $0.312 \mathrm{mg} / 100 \mathrm{~g}$ maize for each accession / varieties. Lectins showed the least concentration in $\mathrm{mg} / 100 \mathrm{~g}$ maize in all the 21 maize accessions / varieties studied. Sammaz 14, 18 and 29 did not differ significantly ( $>0.05$ ) among each other and posses the highest lectin concentration of $0.006 \mathrm{~m} / 100 \mathrm{~g}$ maize in each. Though Sammaz 14, 18 and 29 also appeared significantly $(\mathrm{p}>0.05)$ similar to Sammaz 20, 28 and 34, they remained significantly different $(\mathrm{p}<0.05)$ and higher than other maize accessions / varieties. The least quantity of lectins $0.002 \mathrm{~m} / 100 \mathrm{~g}$ maize was recorded in ENU-E, NSU-P, Sammaz 31, 32 and 37 which did not differ significantly $(p>0.050$ among themselves. Sammaz 27 registered the highest concentration of $0.060 \mathrm{mg} / 100 \mathrm{~g}$ maize of trypsin inhibitor which was statistically similar with $0.050 \mathrm{mg} / 100 \mathrm{~g}$ maize in Sammaz 20 and 28 . Sammaz 37 remained significantly $(p<0.05)$ different from other accessions / varieties but however ENU-E, KAG-W, Sammaz 15, 32, 35 and 37 did not differ significantly $(p>0.05)$ in trypsin inhibitor concentration. The least quantity $(0.010 \mathrm{~g} / 100 \mathrm{~g}$ maize) of trypsin inhibitor was recorded in NSU-P and Sammaz 31 which remained significantly $(\mathrm{p}<0.05)$ different and lower than those of other accessions / varieties.

\section{RESULTS}

Correlation matrix of susceptibility index of S.zeamais INFESTATION ON maize versus anti-nutrients effects

The correlation results in table 2 showed that susceptibility index had though positive but nonsignificant correlations with phytates (r-0.190), oxalates $(r=0.177)$, Tannins $(r=0.102)$, lectins $(\mathrm{r}=0.160)$ and Trypsin inhibitor $(\mathrm{r}=0.106)$. A highly significant positive correlation existed between phytates with oxalates $\left(\mathrm{r}=0.44^{* *}\right)$, Tannins $\left(\mathrm{r}=0.774^{* *}\right)$ lectins $\left(\mathrm{r}=0.589^{* * *}\right)$ and Trypsin inhibitor $\left(\mathrm{r}=0.409^{* *}\right)$. Oxalates showed a significant positive correlation with Tannins $(r=$ $\left.0.326^{*}\right)$ but had highly significant positive correlations with lectins $\left(\mathrm{r}=0.373^{* *}\right)$ and Trypsin inhibitor $\left(\mathrm{r}=0.477^{* *}\right)$. Tannins showed a highly significant positive correlation with lectins $(r=$ $\left.0.695^{* *}\right)$ and Trypsin inhibitor $\left(\mathrm{r}=0.583^{* * *}\right)$ while also, a highly significant correlation $\left(r=0.774^{* * *}\right)$ existed between lectins and trypsin inhibitor. 


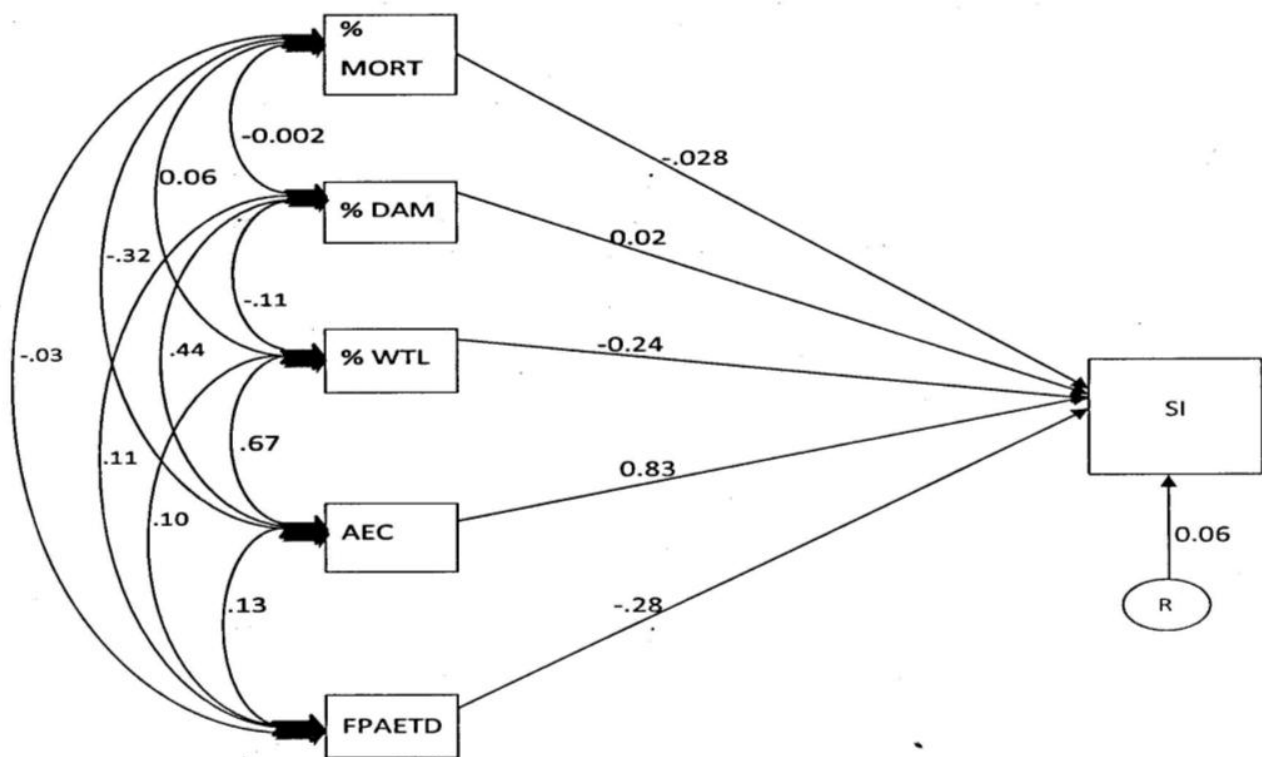

$\%$ MORT $=$ Percentage mortality, \% DAM $=$ Percentage damage, $\%$ WTL $=$ Percentage Weight Loss, AE

- Adult emergence, FPAETD= Fifty percentage adult Emergence Time in days, R=Residual

FIGURE 1: Path diagrams and coefficients of $\boldsymbol{S}$. zeamais development and activities in maize to its susceptibility index (SI)

Table 1: Anti-nutrients composition (mg/100g) of different maize accessions / varieties

\begin{tabular}{cllllll}
\hline Variety & Phytates & Oxalates & Tannins & Lectins & Chemotrypsin inhibitor & Susce. Index (si) \\
\hline Enu-E & $\mathbf{0 . 0 1 8}$ & $\mathbf{0 . 0 1 0}$ & 0.130 & 0.002 & 0.020 & 4.57 \\
KAG -w & $\mathbf{0 . 0 2 2}$ & $\mathbf{0 . 0 2 0}$ & 0.140 & 0.003 & 0.020 & 4.57 \\
NSU-P & 0.010 & 0.020 & 0.130 & 0.002 & 0.010 & 3.47 \\
SAM-11 & 0.072 & 0.040 & 0.460 & 0.004 & 0.040 & 4.67 \\
SAM-14 & 0.038 & 0.040 & 0.380 & 0.006 & 0.040 & 4.10 \\
SAM-15 & 0.058 & 0.040 & 0.480 & 0.004 & 0.020 & 4.13 \\
SAM-16 & 0.022 & 0.020 & 0.460 & 0.003 & 0.040 & 4.11 \\
SAM-17 & 0.044 & 0.060 & 0.410 & 0.004 & 0.040 & 5.06 \\
SAM-18 & 0.044 & 0.040 & 0.440 & 0.006 & 0.040 & 3.66 \\
SAM-20 & 0.026 & 0.040 & 0.400 & 0.005 & 0.050 & 3.16 \\
SAM-26 & 0.046 & 0.040 & 0.420 & 0.004 & 0.040 & 3.72 \\
SAM-27 & 0.024 & 0.060 & 0.280 & 0.004 & 0.060 & 4.40 \\
SAM-28 & 0.050 & 0.050 & 0.360 & 0.005 & 0.050 & 4.83 \\
SAM-29 & 0.048 & 0.040 & 0.480 & 0.006 & 0.040 & 3.50 \\
SAM-31 & 0.014 & 0.020 & 0.140 & 0.002 & 0.010 & 1.79 \\
SAM-32 & 0.016 & 0.020 & 0.180 & 0.002 & 0.020 & 5.84 \\
SAM-33 & 0.042 & 0.050 & 0.270 & 0.004 & 0.040 & 3.55 \\
SAM-34 & 0.048 & 0.040 & 0.420 & 0.005 & 0.030 & 5.33 \\
SAM-35 & 0.022 & 0.030 & 0.120 & 0.003 & 0.020 & 4.63 \\
SAM-37 & 0.023 & 0.070 & 0.140 & 0.002 & 0.020 & 4.03 \\
MEAN & 0.034 & 0.038 & 0.312 & 0.004 & 0.033 & $<.91$ \\
F.LSD(0.05) & 0.0017 & 0.0017 & 0.040 & 0.0017 & 0.017 & $<0.001$ \\
Fpr & $<0.001$ & $<0.001$ & $<0.001$ & $<0.001$ & $<0.001$ & \\
\hline
\end{tabular}

ENU-E = Enugu Ezike, KAG-W = Kagoro-white, NSU-P = Nsukka-Pink, Sam= Sammaz, F-LSD = Fisher's least significance difference. 
Table 2: Correlation matrix of susceptibility index of S.zeamais Festation on maize versus anti-nutrients effects

\begin{tabular}{ccccccc}
\hline \multicolumn{3}{c}{ Variables } & \multicolumn{7}{c}{ Variables } \\
& \%PHY & \% OXL & \%TAN & \%LEC & \% TRY & Corr. Coeff. \\
\hline \%PHY & $\mathbf{0 . 3 8 4 5}$ & 0.0323 & -0.3318 & 0.2417 & -0.0672 & 0.190 \\
$\%$ OXL & 0.1708 & $\mathbf{0 . 0 7 2 6}$ & -0.1336 & 0.1484 & -0.0823 & 0.177 \\
$\%$ TAN & 0.3092 & 0.0235 & $\mathbf{- 0 . 4 1 2 7}$ & 0.2744 & -0.0899 & 0.102 \\
$\%$ LEC & 0.2526 & 0.0293 & -0.3078 & $\mathbf{0 . 3 6 7 9}$ & -0.1042 & 0.160 \\
$\%$ TRY & 0.1720 & 0.0398 & -0.2471 & 0.2553 & $\mathbf{- 0 . 1 5 0 2}$ & 0.106 \\
Residual & & & & & & 0.8535 \\
\hline
\end{tabular}

Note: ** Correlation is significant at the 0.01 level

* Correlation is significant at the 0.01 level

$\mathrm{n}=$ Number of treatments $(20)$

Table 3: Direct and indirect effects of the phytochemcial contents of maize on the susceptibility index (SI) of $S$. zeamais mot.

\begin{tabular}{|c|c|c|c|c|c|c|}
\hline & Susceptibility index SI) & Phytates & Oxalates & Tannins & Lectins & $\begin{array}{l}\text { Trypsin } \\
\text { inhibito }\end{array}$ \\
\hline $\begin{array}{l}\text { Susceptibility index } \\
\text { (SI) }\end{array}$ & 1 & .190 & .177 & .102 & .160 & .106 \\
\hline Phytates & & 1 & $.44^{* *}$ & $.774^{*}$ & $.589^{* *}$ & $.409^{* *}$ \\
\hline Oxalates & & & 1 & $.326^{*}$ & $.373^{* *}$ & $.497^{* *}$ \\
\hline Tannins & & & & 1 & $.695^{* *}$ & $.583^{* *}$ \\
\hline Lectins & & & & & 1 & $.774^{* *}$ \\
\hline Trypsin inhibitor & & & & & & 1 \\
\hline $\begin{array}{l}\text { The dependen } \\
\text { Figures in bol } \\
\% \text { PHY = } \\
\% \text { OXL= Per } \\
\% \text { TA = } \\
\% \text { LEC = } \\
\% \text { TRY = } \\
\mathrm{n}=\text { Number } 0\end{array}$ & $\begin{array}{l}\text { iable is Susceptibility Inde } \\
\text { ints are the direct effects. } \\
\text { entage phytates } \\
\text { ge oxalates } \\
\text { entage Tannins } \\
\text { entage Lectins } \\
\text { entage Trypsin Inhibitor } \\
\text { atments ( } 20\end{array}$ & & & & & \\
\hline
\end{tabular}

Path coefficient analysis of correlation matrix of susceptibility index of S.zeamais infestation on maize versus anti-nutrients effects

The study in table 3 revealed that percentage phytate $(0.3845)$ had a maximum positive direct effect on susceptibility index. It also showed positive indirect effects through percentage lectins $(0.2417)$, percentage oxalates (0.0323) while indirect negative effects were through percentage trypsin inhibitor (-0.0672) and percentage tannins (-0.3318). Percentage lectins (0.3679) also registered a high positive direct effect on susceptibility index, its supportive positive indirect contributions on susceptibility index were through percentage oxalates $(0.0293)$, percentage phytates $(0.2526)$ while the opposing negative indirect effects were through percentage trypsin inhibitor $(-0.1042)$ and percentage tannins $(-0.3078)$. Percentage oxalates $(0.0726)$ showed a positive but negligible direct effect on susceptibility index. Percentage tannins (-0.4127) had a maximum negative direct effect on susceptibility index with a supportive indirect effect from trypsin inhibitor (-0.0899) and opposing inidirect effects from $\%$ phytates (0.3092), \% oxalates $(0.0235)$ and \% lectins $(0.2744)$ followed by percentage trypsin inhibitor $(-0.1502)$. The residual factor obtained is 0.85 which indicates that about $15 \%$ of the variability in susceptibility index (SI) of maize accessions has been explained.

\section{DISCUSSION}

Anti-nutrients are secondary metabolites in plants which help protect them against attack by herbivores. The 20 accessions / varieties of maize used in the experiment contained varied concentrations of phytates, oxalates, tannins, lectins and chymotrpsin inhibitors. From table 1 it can be seen that each of the maize accessions / varieties contained more tannins than other antinutrients. Chukwulobe (2013) reported that the presence of some antinutrients can make nutrients unavailable to the attacking pests because they tie up nutrients, e.g. phytic acid forms insoluble complexes with calcium, zinc, iron and copper.

Falvonoids including tannins chelate metals like iron and zinc thereby reducing their obsorption (Beecher, 2003). Chukwulobe, 2013 reported that antinutrients also inhibit digestive enzymes and precipitate protein, thus even when the pests are there, their growth and reproduction will be greatly discouraged. Antinutrients have been reported to play protective roles in plants (Varm and Dubey, 2005) thereby discouraging 
attack of such plants or plant parts by insect pests (Potenza et al., 2005). Various research reports have shown that these biochemical contents of plants exert their effects in various ways on target pests including, insecticidal, ovicidal, repellent, growth and developmental inhibition (Jbilou et al., 2006; Mamum et al., 2009 and Hatil, 2009). Although the results in table 2, has shown that the susceptibility index of $S$. zeamais on maize grains exhibited very low or negligible positive correlations with phytates, oxalates, Tannins Lectins and Trypsin inhibitor, the path analysis in table 3 shows that \% phytates and \% lectins have moderate and positive direct effects on susceptibility index while \% Tannins had a moderate and negative direct effect on susceptibility index with a supportive indirect effect through \% Try (-0.0899) and opposing positive indirect effects through \% TAN (0.3092), $\%$ oxl (0.0235) and \% LEC (0.2744). These biochemical compounds in the form of phenolic amides such as defeuroyl and dicoumaroyl may be antibiosis factors to the $S$. zeamais (Simbarashe, 2013). Some more recent researchers on resistance to maize weevil in corn grain (Classen et al. 1990, Serratos et al., 1987) have discovered that $90 \%$ of phenolic acid compound, mainly in the form of (E) - furulic acid were found concentrated in the pericarp, testa and aleurone layer of the seeds, which play a very important role in suppressing weevil development, most possibly due to antibiosis effect.

\section{CONCLUSIONS}

All phytochemicals (anti-nutrients) exhibited moderate to high significant positive correlation with each other and all inturn show negligible non significant positive correlation with susceptibility index, and so selection of the maize accessions for resistance base on their association values will be unreliable but the path coefficient analysis indicated that $\%$ tannins had the highest negative direct effect on $S$. zeamais susceptibility/resistance, indicating a better prospect in the selection of accessions with high tannin concentrations for improvement against $S$. zeamais among the maize accessions.

\section{REFERENCES}

Abebe, f., Tefera, T., Mugo, S., Beyene, Y. and Vidal, S. (2009) Resistance of maize varieties to maize weevil Sitophilus zeamais (Mot) (Coleoptera: Curculionidae). African Journal of Biotechnology Vol. 8(21): 5937 - 5943.

Beecher, G.R. (2003). Overview of dietary flavonoids: Nomenclature, occurrence and intake. Journal of nutrition 133 (10): $328-3254$.

Chukwulobe, M.N. (2013). Bioactivity of some plant extracts and coloured polyethylene against Tribolium castaneum (Coleoptera: tenebrionidae) infestation on Musa spps and some root/tuber chips. Msc. Thesis, University of Nigeria, Nsukka.

Classen, D.; Arnason, J.A.; Serratos, J.A.; Lambert, J.D.H.; Nozzolillo and Philogene, B.J.R. (1990) correlation of phenolic acid content of maize to resistance to Sitophilus zeamais, the maize weevil, in COMMIT's collection. J. Chemical.Ecol., 16: $301-315$.

Cordain, L. (2006). “Cereal Grains: Humanity's Double-Edged Sword”. (htt://ww.directms.org./pdf/Evolutionpaleolithic/cereal \%-20sword.pdf) World Review of Nutrition and Dietetics 84:19-73. Doi:10.1159/000059677(http://dx.doi.or g/10.1159\%2F000059677).

Dasbak, M.A.; Echezona, B.C. and Asiegbu, J.E. (2009) Pigeon pea grain physical characteristics and resistance to attack by the bruchid storage pest. International Agrophysics. 23: $19-26$. www. International agrophysics: org.

Derera, J., Pixley, K.V. and Giga, P.D. (2001). Resistance of maize to the maize weevil: 1 Antibiosis. Afri. Crop Sci. 9: $431-$ 440.

Dewey, J.R. and Lu, K.H. (1959). A correlation and path coefficient analysis of components of crested wheat grass and seed production. Agron.J., 51:515-518.

Dobie, P. (1974). The contribution of the tropical stored products center to the study of insect Resistance in stored maize. Tropical Stored Products Information, 34: 7 - 22.

Dobie, P. (1977). The contribution of the tropical stored products center to the study of insect resistance in stored maize. Tropical stored product information. 34: $7-22$.

Gharib, M.S.A. (2004) "Susceptibility of some wheat grain Varieties to Sitophilus oryzae (1.) infestation ", Egypt's Agric Res., 82 (1), 2004.

Hatil, H,E, (2009). "Effects of Certain Medicinal Plant Extracts against storage Pest, Tribolium castaneum. Herbst", Am. 
Eurasian Journal of Sustainable Agriculture.3(2)"139-142, ISSN 1995-0748

Howe, K.W. (1971). A parameter for expressing the suitability of an environment for insect development. Journal of stored product research 7(1), $63-65$.

Jbilou, R., Ennabil, A. and Sayah, F. (2006). "Insecticidal Activity of four Plant Extracts Against Tribolium castaneum (Herbst) (Coleoptera: Tenebrionidae)." African Journal of biotechnology. 5(10). Pp.936-940. Available, online at http://www. Academic journals.org/AJB ISSN: 1684-5315 Academic journals.

Mamum, M.S.A., Shahjahan, M. A. and Ahmad, M. (2009). "Laboratory Evaluation of Some Indigenous Plant Extracts Against Triboluim castaneum. Herbst". Journal. Bangledash Agric. Univ. 7(1): 1-5,ISSN:1810-3030.

Mensah, G.W.K. (1986) "Infestation Potential of Callosobruchus maculatus (F) (Coleoptera: bruchidae) on cowpea stored under subtropical conditions" Insect Sci. Appl., 7(6), 781-784.

Mwololo, J.K. Mugo, S., Tefera, T. and Munyiri, S.W. (2013) Evaluation of traits of resistance to post harvest insect pests in tropical maize. International Journal of Agriculture and crop science. Online www.ijagcs.comIJACS/2013/613/926-933 ISSN 2227-670X (c) 2013 IJACS journal.

Obi, I.U. (2002). Statistical methods of detecting Differences Between Treatment Means and Research Methodology Issues in Laboratory and field Experiments. Ap Express Press, Nsukka.
Ogunniyi, L. (2011). Profit efficiency among maize producers in Oyo state, Nigeria. ARPN Journal of Agricultural and Biological science 6:11 - 17).

Potenza, M.R; Justi, J. and Alves, J.N. (2005) "Evaluation of contact activities of plant extracts against $S$. zeamais Mots Chulsky (Coleoptera: curculionidae. Alternative methods to chemical control", $9^{\text {th }}$ International working Conference on Stored Products Protection Instituto Biologico/APTA,AV. Conselheiro Rodrigues Alves, 1252.Zip code 04014.002-Sao-Paulo, Brazil. Ps7-16203.

Serratos, J.A.; Arnason, J.T.; Nozzolillo, C.; Lambert, J.D.H.; Philogene, B.J.R.; Davidson, K.; Peacock, L.; Atkinson, J. and Morand, P. (1987). Contributions of phenolics antifeedants to resistance of maize to the maize weevil, Sitophilus zeamais. J. Chem.Ecol., 13:751 761.

Simbarashe, M.; James, C. and Sipiwe, G. (2013) Screening of stored maize (Zea mays L.) varieties Grain for tolerance Against maize weevil, Sitophilus zeamais (Motsch.) International Journal of Plant Resea rch 2013, 3(3): 17 22 Doi: $10.5923 / \mathrm{j}$.plant. 20130303.01.

Varma, J. and Dubey, N.K. (2005). Prospective of Botanical and microbial product pesticides of tomorrow. Dept. of Botany, Banaras. Hindu University, Varansi: p. 221. 